УДК 343.2

\title{
О.Н. Рябченко
}

\section{СОВРЕМЕННЫЕ ТЕНДЕНЦИИ ПРИВЛЕЧЕНИЯ К УГОЛОВНОЙ ОТВЕТСТВЕННОСТИ ЗА ВОСПРЕПЯТСТВОВАНИЕ ЗАКОННОЙ ПРЕДПРИНИМАТЕЛЬСКОЙ ИЛИ ИНОЙ ДЕЯТЕЛЬНОСТИ В СВЕТЕ КОНЦЕПЦИИ ЗАЩИТЫ ПРАВ ПРЕДПРИНИМАТЕЛЕЙ}

В современной доктрине уголовного права, при детальном изучении экономических преступлений, расположенных в главе 22 УК РФ, выявлена некоторая тенденция отсутствия системообразующих признаков этой группы преступных посягательств. Проведен серьезный анализ признаков состава преступления, предусмотренного статьей 169 УК РФ, в целях их дальнейшего совершенствования. Целью настоящей работы является изучение правового потенциала статьи и факторов, препятствующих реализации её положений на практике. Достижение поставленной цели возможно путём разрешения таких задач, как выявление правовой природы объективных и субъективных признаков состава преступления по статье 169 УК РФ, исследование проблем применения данной статьи и обозначения возможных путей их разрешения. Установлена актуальность и значимость существования данного состава преступления для защиты интересов предпринимателя в РФ. Выявлены проблемы судебной практики, препятствующие реальному применению положений ст. 169 УК РФ. Сделан акцент на вовлечённость должностных лиц в совершение преступных деяний в отношении субъектов предпринимательской деятельности. Предложены некоторые изменения уголовного законодательства, которые исключат отождествление положений статьи 169 УК РФ с категорией «мёртвой» нормы. В связи с этим представляется вполне оправданным более подробное рассмотрение положений статьи 169 УК РФ, предусматривающей ответственность за воспрепятствование законной предпринимательской или иной деятельности.

Ключевые слова: уголовное право, экономические преступления, предпринимательская деятельность, антикоррупционная политика, оценочные категории, защита предпринимательства, административно-управленческое давление, должностные преступления.

DOI: $10.35634 / 2412-9593-2021-31-5-891-896$

Конституция РФ гарантирует свободу экономической активности и свободное использование способностей и имущества для предпринимательской деятельности (ч. 1 ст. 8, ч. 1 ст. 34) [10]. Развитие и защита предпринимательской деятельности на современном этапе является одним из приоритетных направлений политики РФ [13]. Важной гарантией должна выступать уголовная ответственность, призванная обеспечивать надлежащий порядок осуществления предпринимательской деятельности и охрану самих предпринимателей. Согласно результатам различных исследований, одним из главных барьеров для свободного осуществления предпринимательской деятельности является административное давление [6], которое в большинстве случаев выходит за рамки законного. Из-за этого предприниматели как лица, чья деятельностью полностью основана на риске, оказываются в безвыходной ситуации и вынуждены становится частью коррупционного мира. Соответственно, совершение преступления по ст. 169 УК РФ [18] должностным лицом влечёт, последовательно, наличие такого ряда преступлений, как получение взятки (ст. 290 УК РФ), дача взятки (ст. 291 УК РФ), посредничество во взяточничестве (ст. 291.1 УК РФ). Многие авторы говорят об этом в своих диссертационных исследованиях, обозначая значимость и актуальность исследования [2. С. 4-5; 3. С.10-11; 7. С. 12; 14. С.10; 23. С. 13].

Статья 169 УК РФ, введенная редакцией Федерального закона от 25.06.2002 № 72-Ф3 (ст. 1) [21], направлена на обеспечение осуществления законной предпринимательской деятельности в установленном порядке в целом. Это свидетельствует о специфичном объекте посягательства, имеющем весьма обширный характер [17. С.7-8], охватывающем все экономические отношения с участием предпринимателя, которые могут возникнуть: торговые, инвестиционные, таможенные, налоговые. Важной особенностью статьи является и то, что в ней содержатся оценочные понятия, которые требуют дополнительного изучения: «предпринимательская и иная деятельность», «иное незаконное вмешательство» [4. С. 14-15]. Следует отметить, что на нормативном уровне [19] ст. 169 УК РФ отнесена к перечню преступлений, которые могут способствовать совершению противоправных деяний коррупционной направленности должностным лицом, что ещё раз подтверждает актуальность её изучения, учитывая активную антикоррупционную политику государства $[20 ; 15 ; 16]$. 
Согласно диспозиции настоящей статьи, в объективную сторону преступления входят такие деяния, как неправомерный отказ в государственной регистрации индивидуального предпринимателя (далее - ИП) или юридического лица либо уклонение от их регистрации, неправомерный отказ в выдаче специального разрешения (лицензии) на осуществление определенной деятельности либо уклонение от его выдачи, ограничение прав и законных интересов ИП или юридического лица в зависимости от организационно-правовой формы, незаконное ограничение самостоятельности либо иное незаконное вмешательство в деятельность ИП или юридического лица.

Субъект преступления по ст. 169 УК РФ является специальным - это должностное лицо органа административного управления, полномочное на осуществление определённых действий по регистрации, выдаче лицензии, осуществлению проверочных мероприятий. Совершение противоправного деяния в рассматриваемом составе сопряжено с использованием занимаемого им служебного положения [9. С. 197].

Субъективная сторона преступления выражается в наличии прямого умысла. Мотивы совершения преступления весьма разнообразны, чаще всего являются корыстными, могут быть связаны с местью, обусловлены ложным пониманием интересов службы, целью устранения конкурента, желанием пополнить местный бюджет [1. С. 267]. Цель заключается в воспрепятствовании осуществлению предпринимательской деятельности.

Так, на практике существуют некоторые проблемы, где воспрепятствование выражается не только в тех действиях, которые предусмотрены в статье, но и в совершении любого незаконного деяния должностным лицом, создающим препятствия для субъекта предпринимательской деятельности. В силу широты полномочий административно-управленческого аппарата подобные злоупотребления могут носить самый разнообразный характер. Например, проведение незаконных проверок и ревизий, изъятие документов. Поэтому особое внимание необходимо уделить вопросу, связанному с возможностью отнесения конкретного деяния к «иному вмешательству». Что понимается под «иным вмешательством»? Ответ на данный вопрос отсутствует как в законодательстве, так и в правоприменительной практике.

Вместе с тем отсутствует легальное толкование и законодательное закрепление характеристики понятий «неправомерный отказ», «уклонение», «незаконное ограничение», не закреплены признаки, позволяющие отнести деяние к иному вмешательству, не установлены общие принципы урегулирования трудностей при решении соответствующего вопроса. В связи с этим возникают затруднения относительно возможности отнесения того или иного действия или бездействия к преступному в рамках ст. 169 УК РФ. Разработка признаков или критериев относимости просто необходимы для дальнейшего существования состава преступления, закреплённого ст. 169 УК РФ.

Недостаточная определённость положений диспозиции статьи вызывает проблемы и при разграничении рассматриваемого состава со смежными, например, ст. 285 УК РФ. Исходя из общепринятых положений доктрины уголовного права ст. 169 УК РФ является специальной по отношению к ст. 285 УК РФ. Вместе с тем при определённых обстоятельствах дела лицу вменяется ст. 285 УК РФ вместо 169 УК РФ. Позиция суда заключается в том, что превышение должностных полномочий охватывает деяния, предусмотренные ст. 169 УК РФ при отсутствии совокупности [12]. По обстоятельствам дела ООО П. с основным видом предпринимательской деятельности, связанной со строительством зданий, было выдано разрешение на строительство. Однако в дальнейшем Т., являющийся исполняющим обязанности начальника Главного управления архитектуры и градостроительства, стремясь угодить начальству, создать о себе благоприятное мнение у руководства, подписал приказ об отмене данного разрешения. Изначально органами предварительного следствия лицу вменялась ч. 1 ст. 169 УК РФ. Подробный анализ дела, действительно, не даёт оснований усомниться в правильности вынесенного судом решения. Вынося такой приговор, суд руководствовался обоснованным теоретическим положением, согласно которому при квалификации совершённого преступления учитывается наиболее полный охват действий лица положениями конкурирующих норм. Если норма ст.169 УК РФ является недостаточно чёткой и не позволяет однозначно говорить о наличии или отсутствии именно указанных в ней действий в поведении лица, то положения ст. 285 УК РФ компенсируют данные несовершенства и применяются без сомнений.

Вызывает вопросы и несоответствие санкции, предусмотренной ст. 169 УК РФ, степени общественной опасности преступления. Максимально возможным наказанием по основному составу, закреплённому в ч. 1 ст. 169 УК РФ, являются обязательные работы на срок до 360 часов. В то время 
как общая норма по ч. 1 ст. 285 УК РФ предусматривает лишение свободы на срок до 4 лет. Можно ли при такой законодательной позиции говорить о реальной защите интересов субъектов предпринимательской деятельности? Представляется целесообразным внести изменения в санкцию ст. 169 УК РФ, закрепив возможность привлечения к такому наказанию, как лишение свободы на срок до 6 лет.

Серьезной проблемой, возникающей при расследовании преступления в целях вменения лицу ст. 169 УК РФ, является уголовно-процессуальное доказывание. Сотрудникам правоохранительных органов необходимо доказать, что лицо, совершая то или иное действие или бездействие, осознавало общественную опасность для установленного порядка осуществления предпринимательской деятельности, предвидело общественно опасные последствия для такого субъекта и желало их наступления. Однако на практике установить вину именно в отношении входящих в объективную сторону состава преступления деяний достаточно затруднительно, а в некоторых случаях практически невозможно [8. С. 41]. Б. был признан виновным в совершении преступления по ч. 1 ст. 169 УК РФ за воспрепятствование законной предпринимательской деятельности, то есть ограничение прав и законных интересов юридического лица, совершенное должностным лицом с использованием своего служебного положения. Однако определением судебной коллегии по уголовным делам Верховного Суда РФ был отменён приговор нижестоящего суда, а уголовное дело прекращено за отсутствием состава преступления [11]. При этом в судебном решении было указано: «Выводы суда о виновности Б. в совершении преступления не могут быть признаны обоснованными», признаки состава преступления, предусмотренные ст. 169 УК РФ, в деянии подсудимого не усматриваются.

Связана такая тенденция не только со сложностью сбора достаточной доказательственной базы, но и с латентным характером данных преступлений. Действительно, сложно представить, сколько преступлений, формально подпадающих под действие ст. 169 УК РФ, совершается в настоящей момент в сложившихся в стране экономических условиях. Конкурентная среда осуществления предпринимательской деятельности, большой финансовый риск и страх потерь, значительный контроль со стороны органов власти и управления не оставляют для субъектов хозяйственной деятельности другого выбора кроме решения всех возникающих вопросов на месте, чаще всего путём дачи взятки.

Многие учёные в области уголовного права относят ст. 169 УК РФ к числу «мёртвых»норм» [22. С. 29]. Действительно, положения ст. 169 УК РФ характеризуются сложным процессом доказывания деяния, предусмотренного диспозицией статьи Особенной части УК РФ, проблемами уголовноправовой квалификации деяния при наличии смежных составов, слишком мягкой санкцией. Учитывая вышеизложенное, можно говорить о практической невозможности реализации положений рассмотренного состава преступления. В пользу такого тезиса говорят и следующие статистические данные: по данным Судебного департамента при ВС РФ в 2017 г. по ст. 169 УК РФ осуждено только 5 человек, из них назначено наказание в виде штрафа - четверым, в 2018 г. осуждено 7 лиц, а в 2019 г. - 9, из которых ни одному не назначено наказание в виде лишения свободы [5].

Таким образом, необходимо отметить, что для достижения тех правовых целей, которые поставлены перед современным уголовным законодательством, следует внести некоторые изменения в положения ст. 169 УК РФ. Необходимо сконструировать её диспозицию так, чтобы деяния, указанные в качестве преступных, соответствовали фактическим реалиям. Возможным вариантом решения проблемы является введение критериев или признаков преступного деяния, направленного на воспрепятствование предпринимательской деятельности. Причём существующее в настоящий момент последовательное перечисление деяний, имеющее неисчерпывающий перечень, должно исключаться. На необходимость отказа от перечисления в объективной стороне состава преступления по ст. 169 УК РФ ранее уже обращалось внимание [14. С. 8]. В качестве указанных критериев или признаков предлагаются к рассмотрению следующие.

1. Необходимость обращения к положениям гражданского законодательства, многочисленным подзаконным актам для выявления сути совершаемых в отношении предпринимателей административно-управленческих процедур и процессов, например, при регистрации в качестве юридического лица или возникновении необходимости в продлении лицензии.

2. Совершение действия или бездействия в отношении субъекта предпринимательской деятельности входит в круг полномочий должностного лица.

Должностное лицо всегда наделено закреплённым в законодательстве кругом прав и обязанностей. Совершаемое им деяние, как правило, входит в указанный перечень. 
3. Формальная обоснованность принимаемых должностными лицами решений, имеющих значение для предпринимательской деятельности. Итоговое решение по тому или иному делу всегда принимается должностным лицом со ссылкой на нормативные положения. На первый взгляд возможность оспаривания таких правоприменительных актов исключена.

4. Факт причинения ущерба субъекту предпринимательской деятельности или реальной возможности его возникновения, то есть в результате действия или бездействия должностного лица предприниматель несёт или должен будет нести дополнительное материальное бремя, которое может выражаться в необходимости произвести денежные расходы или лишиться иного движимого или недвижимого имущества.

5. Наличие искусственно созданного препятствия, которое подразумевает под собой предъявление к деятельности субъекта предпринимательства дополнительных требований по инициативе должностного лица или таких требований, которые не предусмотрены законодательством, а также целенаправленное создание условий, исключающих возможность продолжения деятельности.

6. Невозможность при разумной степени вовлечённости предпринимателя устранить обстоятельства - основания отказа или бездействия органов и должностных лиц, препятствующих дальнейшему осуществлению предпринимательской деятельности.

В этом случае к субъекту предпринимательской деятельности предъявляются такие требования, удовлетворить которые он не может даже при наличии временных и финансовых ресурсов, не говоря о возможности ситуации, при которой они имеются у него в ограниченном количестве. Например, сбор малозначащей документации при сложной процедуре её получения или истребование документов, получение которых заведомо невозможно, необходимость в оплате искусственно созданных сборов в пользу местного бюджета, устранения «препятствий» личного характера: наличие брака, родственная связь с «нежелательным» лицом.

7. Факт последовательного целенаправленного совершения должностным лицом ряда действий или бездействий, приводящих к воспрепятствованию.

Об этом могут свидетельствовать предварительная беседа с лицом, желающим стать ИП, предъявление к нему каких-либо дополнительных требований в устной форме, условный устный отказ в регистрации ИП в таком качестве.

Исходя из вышеизложенного нами предлагается под «иным вмешательством» понимать любое действие или бездействие должностного лица органа управления, имеющее своей целью воспрепятствование осуществлению законной предпринимательской деятельности и отвечающее одному и (или) нескольким следующим признакам преступности деяния по ст. 169 УК РФ.

Несомненно, закрепление вышеуказанных критериев непосредственно в Уголовном законе либо их изложение в обобщающих правоприменительных актах Верховного Суда РФ повлечёт дальнейшее развитие законодательных положений, станет основой для формирования более обширной судебной практики. Тем более что указанные нововведения связаны с реализацией прав субъектов предпринимательской деятельности, от успешного развития которой зависит благополучие всего гражданского общества и государства.

\section{СПИСОК ЛИТЕРАТУРЫ}

1. Бриллиантов А.В. Уголовное право России. Части Общая и Особенная. М., 2016. 1184 с.

2. Вербицкая Ю.В. Уголовно-правовые и криминологические меры борьбы с воспрепятствованием законной предпринимательской или иной деятельности: автореф. дис. ... канд. юрид. наук: 12.00 .08 / Академия экон. безопасности МВД России. М., 2006. 28 с.

3. Ворожко К.А. Незаконное вмешательство должностных лиц в предпринимательскую деятельность: уголовно-правовые аспекты: автореф. дис. ... канд. юрид. наук: 12.00.08 / Ростовский юрид. ин-т МВД РФ]. Ростов н/ Д., 2011. 23 c.

4. Вольдимарова Н.Г.Актуальные проблемы уголовной ответственности за экономические преступления: монография. М.: Проспект, 2020. 189 с.

5. Судебный департамент при Верховном Суде Российской Федерации: Официальный сайт. URL: http://www.cdep.ru/iniddex.php?=5 (дата обращения: 21.03.2021).

6. Всероссийский центр измерения общественного мнения: Официальный сайт. Режим доступа. URL: https://profi.wciom.ru/fileadmin/file/nauka/podborka/wciom_sociodigger (дата обращения: 25.03.2021).

7. Карпович О.Г. Уголовно-правовая охрана предпринимательской деятельности в России и странах Европы : автореферат дис. ... докт. юрид. наук: 12.00.08. Моск. гос. юрид. акад. М., 2003. 61 с. 
8. Коваленко Т.С. Проблемы привлечения к уголовной ответственности по статье 169 УК РФ за воспрепятствование законной предпринимательской или иной деятельности // Российский следователь. 2020. № 2. С. 38-42.

9. Комментарий к Уголовному кодексу Российской Федерации: в 4 т. (постатейный) / А.В. Бриллиантов, А.В. Галахова, В.А. Давыдов и др.; отв. ред. В.М. Лебедев. М.: Юрайт, 2017. Т. 2: Особенная часть. Разделы VII-VIII. C.197. $371 \mathrm{c}$.

10. Конституция Российской Федерации» (принята всенародным голосованием 12.12.1993 с изменениями, одобренными в ходе общероссийского голосования 01.07.2020) // Российская газета. Федеральный выпуск. 2020. 4 июля.

11. Определение Судебной коллегии по уголовным делам Верховного Суда Российской Федерации от 12.11.2019 № 3-УД19-11 // СПС «КонсультантПлюс».

12. Приговор Октябрьского районного суда г. Ижевска Удмуртской Республики от 15 августа 2017 г. по делу № 1-151/2017 (09/1295-2016) // СПС «КонсультантПлюс».

13. Распоряжение Правительства РФ от 02.06.2016 № 1083-р (ред. от 30.03.2018) «Об утверждении Стратегии развития малого и среднего предпринимательства в Российской Федерации на период до 2030 года»// Собрание законодательства РФ. 2016. № 24. Ст. 3549.

14. Рудовер Е.А. Воспрепятствование законной предпринимательской или иной деятельности: уголовноправовой и криминологический аспекты: автореф. дис. ... канд. юрид. наук: 12.00.08 / Моск. ун-т МВД РФ. M., 2004. 24 c.

15. Указ Президента РФ от 19.05.2008 № 815 (ред. от 13.05.2019) «О мерах по противодействию коррупции» // Российская газета. 2008. 22 мая.

16. Указ Президента РФ от 14.02.2014 № 80 «О некоторых вопросах организации деятельности по противодействию коррупции» // Собрание законодательства РФ. 2014. №7. Ст. 672.

17. Леонов М.Г. Уголовная ответственность за воспрепятствование законной предпринимательской или иной деятельности: автореф. дис. ... канд. юрид. наук: 12.00 .08 / Тамбовский гос. ун-т им. Г.Р. Державина. Саратов, 2009. 29 с.

18. Уголовный кодекс Российской Федерации от 13.06.1996 № 63-Ф3 (ред. от 24.02.2021) // Собрание законодательства РФ. 1996. № 25. Ст. 2954.

19. Указание Генпрокуратуры России № 35/11, МВД России № 1 от 24.01.2020 (ред. от 13.07.2020) «О введении в действие перечней статей Уголовного кодекса Российской Федерации, используемых при формировании статистической отчетности».

20. Федеральный закон от 25.12.2008 № 273-Ф3 (ред. от 31.07.2020) «О противодействии коррупции» // Российская газета. 2008. 30 дек.

21. Федеральный закон от 25 июня 2002 г. № 72-Ф3 «О внесении изменений в статьи 169 и 171 Уголовного кодекса Российской Федерации» // Российская газета. 2002. 28 июня.

22. Цепелев К.В., Чернявский Д.О. Проблемы противодействия воспрепятствованию законной предпринимательской или иной деятельности уголовно-правовыми средствами // Безопасность бизнеса. 2020. № 6. С. 27-31.

23. Шпилева В.А. Уголовно-правовая охрана предпринимательства: автореф. дис. ... канд. юрид. наук: 12.00 .08 / Науч. -исслед. ин-т ФСИН. М., 2006. 32 с.

Поступила в редакцию 28.06.2021

Рябченко Оксана Николаевна, кандидат юридических наук, доцент кафедры уголовного права и криминологии ФГБОУ ВО «Удмуртский государственный университет» 426034, Россия, г. Ижевск, ул. Университетская, 1 (корп. 4) E-mail: Okt.wa@yandex.ru

\section{O.N. Ryabchenko \\ CURRENT TRENDS IN BRINGING TO CRIMINAL RESPONSIBILITY FOR OBSTRUCTING LEGITIMATE ENTREPRENEURIAL OR OTHER ACTIVITIES IN THE LIGHT OF THE CONCEPT OF PROTECTING THE RIGHTS OF ENTREPRENEURS}

DOI: 10.35634/2412-9593-2021-31-5-891-896

In the modern doctrine of criminal law, a detailed study of economic crimes located in Chapter 22 of the Criminal Code of the Russian Federation revealed a certain tendency of the absence of system-forming signs of this group of criminal encroachments. A serious analysis of the signs of the corpus delict provided for in Article 169 of the Criminal Code of the Russian Federation was carried out in order to further improve them. The purpose of this work is to study the legal potential of the article and the factors that prevent the implementation of its provisions in practice. Achieving this goal 
is possible by solving such tasks as identifying the legal nature of objective and subjective signs of a crime under Article 169 of the Criminal Code of the Russian Federation, studying the problems of applying this article and identifying possible ways to resolve them. The relevance and significance of the existence of this corpus delict for the protection of the interests of an entrepreneur in the Russian Federation is established. The problems of judicial practice that prevent the real application of the provisions of Article 169 of the Criminal Code of the Russian Federation are identified. The emphasis is placed on the involvement of officials in the commission of criminal acts against business entities. Some changes in the criminal legislation are proposed, which will exclude the identification of the provisions of Article 169 of the Criminal Code of the Russian Federation with the category of "dead" norms. In this regard, it seems quite justified to consider in more detail the provisions of Article 169 of the Criminal Code of the Russian Federation, which provides for liability for obstruction of legitimate entrepreneurial or other activities.

Keywords: criminal law, economic crimes, entrepreneurial activity, anti-corruption policy, evaluation categories, protection of entrepreneurship, administrative and managerial pressure, official crimes.

Received 28.06.2021

Ryabchenko O.N., Candidate of Law, Associate Professor at Department of Criminal Law and Criminology Udmurt State University

Universitetskaya st., 1/4, Izhevsk, Russia, 426034

E-mail: Okt.wa@yandex.ru 